\title{
RESPOSTA DO SORGO GRANÍFERO A DÉFICITS HÍDRICOS APLICADOS DURANTE O CICLO DE DESENVOLVIMENTO DA CULTURA
}

\author{
GRAIN SORGHUM RESPONSES UNDER WATER DEFICITS \\ ON DIFFERENT GROWTH STAGES
}

\author{
Reimar Carlesso $^{1}$ Marcia Xavier Peiter ${ }^{2}$ Mirta Terezinha Petry ${ }^{3}$ Dolores Woschick ${ }^{3}$
}

RESUMO

Os objetivos deste experimento foram analisar os efeitos de déficits hídricos aplicados durante o ciclo de desenvolvimento da cultura do sorgo granífero sobre o dossel vegetativo, senescência das folhas, número e comprimento final de entre-nós. $O$ experimento foi conduzido em um conjunto de lisímetros de drenagem protegidos das precipitações por uma cobertura móvel de plástico transparente. A cultivar Agroceres 3001 foi submetida a quatro tratamentos: bem irrigado, déficit hídrico terminal, déficit hídrico durante o crescimento vegetativo e déficit hídrico após a antese, em três repetições. Os resultados indicaram que o dossel vegetativo das plantas de sorgo foi reduzida quando a fração de água disponível às plantas for inferior a 0,60. O comprimento final dos entre-nós das plantas foi reduzido para déficits hídricos aplicados a partir e durante a fase de crescimento vegetativo. A senescência das plantas de sorgo foi ativada quando a fração de água disponível às plantas foi inferior a 0,50 na profundidade do solo explorado pelo sistema radicular das plantas.

Palavras-chave: irrigação, dossel vegetativo, área foliar, senescência, lisímetros.

\section{SUMMARY}

The objective of this experiment was to analyze the water deficit effects on grain sorghum growth, crop canopy, leaf senescence and inter-node length. The experiment was conduced in a set of drainage lysimeters protected by a rain shelter. The

\begin{abstract}
Agroceres 3001 variety was submitted to four treatments: well irrigated, terminal water deficit, pre-anthesis soil water deficit and, post-anthesis water deficit, with three replications. Results indicated that crop canopy was reduced when the fraction of plant available water was reduced to values lower than 0.60. The internode length was reduced for soil water deficit applied during vegetative crop growth. Leaf senescence was activated when the fraction of plant available water was lower than 0.50 in the root system explored depth.
\end{abstract}

Key words: irrigation, crop canopy, leaf area, senescence, lysimeters.

\section{INTRODUÇÃO}

O sorgo caracteriza-se por responder relativamente bem a pequenas quantidades de água, aplicadas nas épocas críticas, influenciando diretamente a produção de grãos (ASSOCIAÇÃO BRASILEIRA DE MILHO E SORGO, 1989) e, por adaptar-se a condições tanto áridas quanto úmidas, em áreas marginais, onde outras culturas normalmente não são utilizadas (ARKIN et al., 1976). Existem, no entanto, discrepâncias na literatura a respeito dos períodos críticos desta cultura em relação ao déficit hídrico. DOORENBOS \& PRUITT (1977) afirmam

${ }^{1}$ Engenheiro Agrônomo, Bolsista do CNPq, Professor Titular, PhD, Departamento de Engenharia Rural, Universidade Federal de Santa Maria. 97119-900. Santa Maria, RS. Autor para correspondência.

${ }^{2}$ Aluna do Curso de Pós-graduação em Hidráulica e Saneamento, Escola de Engenharia de São Carlos, Universidade de São Paulo. São Carlos, SP.

${ }^{3}$ Aluna do Curso de Agronomia, Universidade Federal de Santa Maria. Santa Maria, RS. 
que a cultura do sorgo granífero é mais sensível ao déficit hídrico somente durante o período de enchimento de grãos. Entretanto, FERREIRA et al. (1992) verificaram que o déficit hídrico aplicado após a antese não induziram variações significativas na área foliar, na massa seca total da parte aérea, no comprimento médio de panículas e na massa de grãos. Estes autores observaram também que o déficit hídrico antes da antese ocasiona reduções na produção de grãos e diminuição do acúmulo de reservas nos colmos.

Estudos têm demonstrado que a taxa de expansão da área foliar do dossel vegetativo é reduzida em muitas culturas, por déficits hídricos, quando a fração de água disponível (FAD) for de aproximadamente 0,50 na profundidade do perfil do solo explorado pelo sistema radicular das plantas (RITCHIE, 1981; ROSENTHAL et al., 1987). Nas folhas, o déficit hídrico reduz a taxa de emergência (MUCHOW \& CAMBERRY, 1990), a taxa de expansão (STOUT et al., 1978) e aumenta o período de expansão (ROSENTHAL et al., 1987). O resultado é uma redução na taxa de aumento da área foliar do dossel e um menor dossel vegetativo quando completamente expandido.

A senescência das folhas reduz a área foliar do dossel vegetativo e sua severidade é dependente do período de ocorrência e da duração do déficit. A senescência quando comparada com a elongação das folhas tem sido apresentada com um processo menos sensitivo ao déficit hídrico durante o crescimento vegetativo (CARLESSO, 1993). Uma elevada taxa de senescência foi encontrada por ROSENTHAL $\boldsymbol{e t} \boldsymbol{a l}$. (1987) em plantas mantidas com FAD inferior a 0,30, na profundidade do perfil do solo explorado pelo sistema radicular. A senescência das folhas é induzida pelo déficit hídrico durante o enchimento dos grãos e é aumentada caso a planta possua um elevado número de grãos por unidade de área foliar (WOLFE et al., 1988).

Apesar da abundante literatura a respeito dos efeitos qualitativos da deficiência hídrica sobre a cultura do sorgo, poucos experimentos procuraram quantificar estas respostas. Este experimento teve como objetivos quantificar os efeitos de déficits hídricos em três períodos do ciclo da cultura do sorgo granífero sobre a expansão do dossel vegetativo, senescência das folhas, úmero e comprimento final de entre-nós.

\section{MATERIAIS E MÉTODOS}

O experimento foi desenvolvido em área experimental do Departamento de Engenharia Rural, no Campus da Universidade Federal de Santa Maria, no ano agrícola de 1993/94, em um conjunto de lisímetros de drenagem, com dimensões de 1,40 x $0,95 \mathrm{~m}$ e profundidade de $1,0 \mathrm{~m}$, protegidos das precipitações pluviométricas por uma cobertura móvel de plástico transparente. O solo da área experimental foi classificado como Podzólico vermelho-amarelo. O sorgo granífero, cultivar Agroceres 3001, foi submetido a quatro tratamentos: (i) bem irrigado (irrigações foram aplicadas para manter a FAD superior a 0,95 no período de 33 a 104 dias após a emergência - DAE); (ii) déficit terminal (as irrigações foram suspensas aos $33 \mathrm{DAE}$ ); (iii) déficit hídrico aplicado antes da antese (irrigações foram suspensas no período de 33 a $67 \mathrm{DAE}$ ), e (iv) déficit hídrico aplicado após a antese (irrigações foram suspensas no período de 51 a 83 DAE). As irrigações somente foram suspensas durantes os períodos de aplicação dos déficits hídricos nos diferentes tratamentos. Irrigações foram realizadas antes e depois dos períodos de aplicação dos déficits hídricos nos diferentes tratamentos para manter a FAD superior a 0,95 , na profundidade efetiva do sistema radicular das plantas. $\mathrm{O}$ delineamento experimental utilizado foi inteiramente casualizado, com três repetições. A semeadura foi realizada, em linhas, no dia 20 de novembro de 1993. Semearam-se 22 plantas por parcela, perfazendo, aproximadamente, uma população de 165.000 plantas por hectare.

Aos cinco DAE selecionaram-se cinco plantas por parcela para determinações não destrutivas da área foliar das plantas, senescência e elongação das folhas. A determinação da área foliar foi realizada, desde o aparecimento das folhas no cartucho, até o surgimento da bainha. A área foliar das plantas foi calculada através do produto das medidas do comprimento e largura de cada folha, multiplicada pelo coeficiente de 0,75 (STICKLER $\boldsymbol{e t}$ al., 1961). As observações de senescência em cada folha da planta foram realizadas visualmente, estabelecendo-se uma escala de 0 a $100 \%$, que correspondiam às folhas totalmente verdes e totalmente senescentes, respectivamente. A área foliar senescida das plantas foi determinada pela diferença entre a área foliar máxima e a área fotossinteticamente ativa das plantas. A expansão das folhas foi determinada, nas folhas em crescimento, pela medida do comprimento visível das folhas, através de uma régua, desde a extremidade da folha até o ponto de encontro das laterais da folha junto ao cartucho. A expansão relativa das folhas foi calculada para as plantas submetidas a déficit hídrico terminal pela razão entre a taxa de expansão média de todas as folhas em crescimento e a taxa de expansão média das folhas de plantas bem irrigadas, no intervalo 
entre duas determinações consecutivas. A medição do comprimento final dos entre-nós foi realizada na colheita, aos 104 DAE, através da determinação da distância entre dois nós consecutivos do colmo das plantas. O número da folha do nó inferior foi utilizado para identificar o comprimento do entre-nó.

O conteúdo de água no solo foi monitorado a partir de $10 \mathrm{DAE}$, aproximadamente, três vezes por semana, com sonda de nêutrons HYDROPROBE CPN 503DR até a profundidade de 1,0m. A determinação da FAD foi realizada de acordo com metodologia descrita por CARLESSO (1995). A capacidade de água disponível (CAD) determinada pela diferença entre o limite superior e o inferior de disponibilidade de água às plantas na profundidade do perfil do solo explorado pelo sistema radicular das plantas foi de $161,1 \mathrm{~mm}$. Considerou-se como limite superior, a quantidade da água retida no perfil do solo, previamente saturado, após cessar a drenagem; e, como limite inferior a quantidade da água armazenada no perfil, após toda a extração possível realizada por plantas desenvolvidas normalmente. As doses de irrigação utilizadas foram calculadas elevando-se o conteúdo de água no perfil dos limites inferiores estabelecidos pelos tratamentos até o limite superior. Assim, irrigações foram aplicadas quando a CAD medida no perfil do solo explorado pelo sistema radicular era inferior a $153 \mathrm{~mm}(\mathrm{FAD}=$ $0,95)$, para elevar o valor até $161,1 \mathrm{~mm}$. Nos demais tratamentos, as irrigações foram semelhantes ao tratamento bem irrigado, durante os períodos sem déficit hídrico.

\section{RESULTADOS E DISCUSSÃO}

A expansão relativa das folhas das plantas de sorgo, submetidas a déficit hídrico terminal e a déficit antes da antese, é apresentada na Figura 1. Uma redução acentuada na expansão relativa foi observada quando a FAD foi reduzida para valores inferiores a 0,60 e, a expansão das folhas das plantas submetidas a déficit hídrico foi inferior a $10 \%$ da elongação observada nas plantas bem irrigadas quando a FAD foi de aproximadamente 0,30. Este decréscimo na expansão foliar tem como consequência uma acentuada redução na área foliar fotossinteticamente ativa das plantas com reflexos na produtividade da cultura. De acordo com CARLESSO (1993) e ROSENTHAL et al. (1987), valores de aproximadamente 0,30 da FAD são considerados como limite crítico onde a expansão das folhas é mínima e a senescência é acelerada, com aumento na resistência estomática, redução no processo transpiratório e na atividade fotossintética, além de redução na acumulação de matéria seca e na produção de grãos. Os resultados deste experimento indicaram que a FAD crítica, a partir da qual ocorre redução na expansão das folhas de sorgo, foi de 0,60. Este valor é superior aos apresentados por RITCHIE (1981) e ROSENTHAL et al. (1987) que verificaram o início da redução da expansão das folhas quando a FAD foi inferior a 0,50. Esta diferença embora seja de $10 \%$, em termos numéricos, representa $16 \mathrm{~mm}$ de água disponível às plantas que em situações de déficit hídrico associado com baixa demanda evaporativa do ar podem retardar em vários dias a ocorrência de reduções irreversíveis na área foliar fotossinteticamente ativa das plantas.

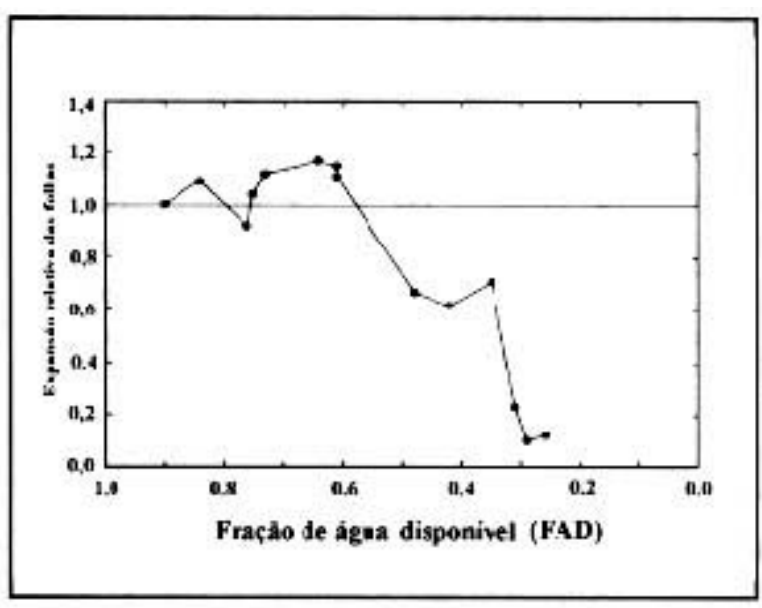

Figura I Variação da expansão relativa das fol has das plantas de sorgo submetidas a deficit hidr iue can ielaçabs a fizçâu de água disponivel as plantas Santa Maria - FS, 1994

Plantas submetidas a déficit hídrico terminal e déficit hídrico aplicado antes da antese apresentaram uma progressiva redução na FAD a partir de 33 DAE (Figura 2). No entanto, uma redução mais acentuada na FAD foi observada entre 33 e 44 DAE, correspondendo a uma evapotranspiração média de $3,8 \mathrm{~mm} \mathrm{dia}^{-1}$ no período. Entretanto, uma menor redução dos valores da FAD foi observada em relação ao tempo, no período compreendido entre 44 e 67 DAE, representando uma evapotranspiração média de

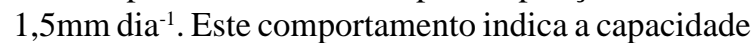
de adaptação das plantas de sorgo a redução na disponibilidade de água potencialmente transpirável. Aos 67 DAE as plantas submetidas a déficit antes da antese foram irrigadas e, consequentemente, um rápido incremento na FAD foi observado. No período compreendido entre 67 e 97 DAE a evapotranspiração média das plantas submetidas a déficit hídrico terminal 
foi de $0,59 \mathrm{~mm} \mathrm{dia}^{-1}$. Aos 97 DAE as plantas submetidas a déficit hídrico terminal apresentaram somente $17,7 \mathrm{~mm}$ de água disponível armazenada no perfil do solo explorado pelo sistema radicular das plantas. Plantas submetidas a déficit hídrico após a antese apresentaram uma progressiva redução nos valores da FAD correspondendo a uma evapotrans-piração média no período de déficit de $2,11 \mathrm{~mm} /$ dia. No entanto, não foi observado uma redução na taxa de evapotranspiração com o aumento da intensidade do déficit hídrico.

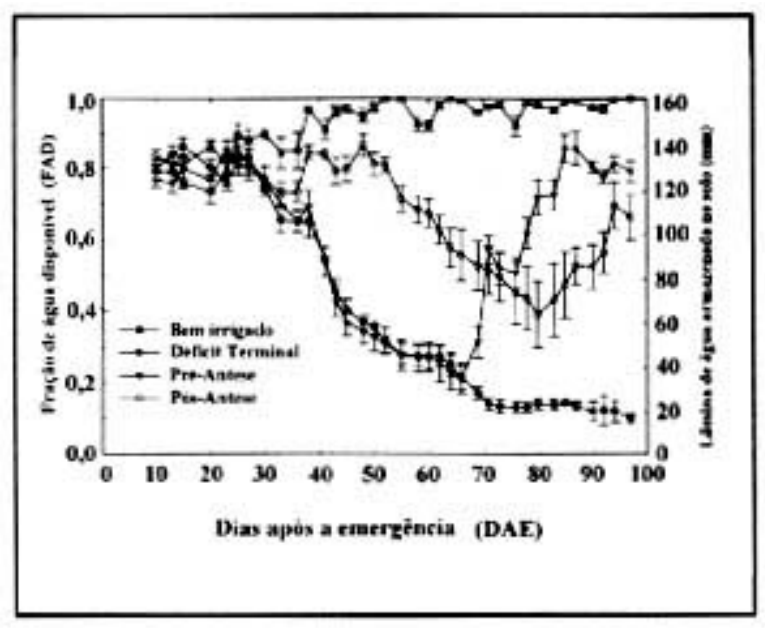

Figura 2 - Vaariaçăo da fraçào de ảgua disponivel às plantis (FAD) e da lämina de agua armazenada no perfil do solo ao longo do ciclo de crescimento do sorgo. A amplitude das bartas verticais representam o desvio padrio.

Uma progressiva redução no comprimento final dos entre-nós foi verificada entre os entre-nós 4 e 9 (Figura 3). Ocorreu um incremento no comprimento dos entre-nós tanto para as plantas bem irrigadas como para as plantas submetidas a déficit hídrico aplicado após a antese a partir do entre-nó 9. Plantas submetidas a déficit hídrico durante o período de crescimento vegetativo (déficit hídrico terminal e pré-antese) apresentaram entre-nós intermediários de menor comprimento. Entretanto, o menor comprimento dos entre-nós verificado nas plantas submetidas a déficit hídrico terminal foi devido a supressão total da irrigação a partir dos 33 DAE. A interrupção do déficit hídrico no tratamento pré-antese (durante o período de crescimento vegetativo) possibilitou uma maior expansão dos entre-nós, no entanto, o número total de entre-nós foi semelhante ao observado para as plantas bem irrigadas. Este resultados indicaram que a ocorrência de déficit hídrico durante o desenvolvimento vegetativo das plantas de sorgo ocasiona uma redução no comprimento dos entre-nós mas não afeta o número de entre-nós, consequentemente não havendo redução no número total de folhas. Plantas submetidas a déficit hídrico terminal apresentaram uma redução de 48,9\% no comprimento médio dos entre-nós em relação a plantas bem irrigadas, além de apresentarem um menor número de entre-nós (dois) e conseqüentemente menor número de folhas. Comportamento semelhante também foi obtido no experimento conduzido por ROSENTHAL et al. (1987). Estes autores afirmam que a intensidade de ocorrência de um déficit hídrico pode ser avaliada por diversas formas, entre elas a redução na altura final de plantas. NeSMITH \& RITCHIE (1992) relatam que o número e o comprimento final dos entre-nós podem também ser considerados como indicadores de déficits hídricos. Relacionando o comprimento dos entre-nós (Figura 3) com a FAD (Figura 2) verifica-se que para o déficit terminal os valores da FAD foram inferiores a 0,60 após os 40 DAE, período em que as plantas apresentavam bainhas visíveis até a folha de número 9. Estes resultados estão de acordo com PEITER \& CARLESSO (1996) que observaram reduções na altura final de plantas de sorgo submetidas a diferentes níveis de déficit hídrico ao longo do ciclo de desenvolvimento das plantas.

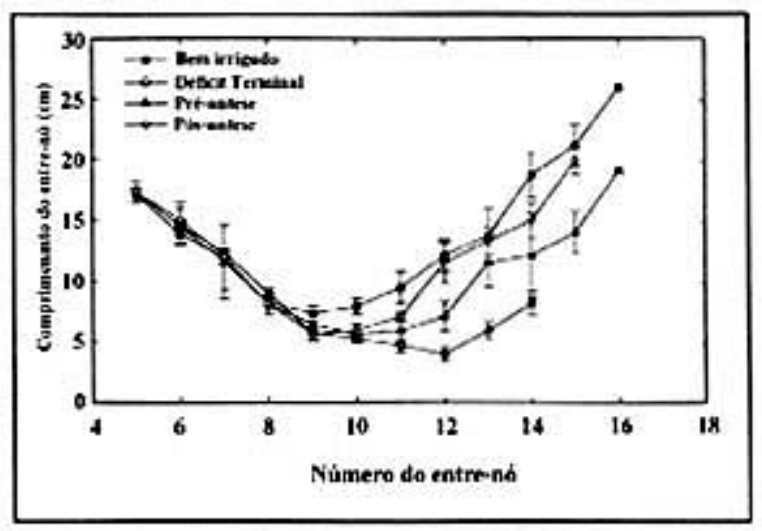

Figura 3 - Comprimento médio final dos entre-nós do colmo das plantas de sorgo submetidas aos diferentes manejos da água de irrigaçà. A amplitude das barras verticais representam o desvio padrao. Santa Maria-RS. 1994.

As plantas de sorgo submetidas a déficit hídrico terminal apresentaram um aumento progressivo da senescência das folhas após a interrupção das irrigações (Figura 4). Um comportamento semelhante foi observado para as plantas submetidas a déficit hídrico antes da antese. Entretanto, após a interrupção do déficit hídrico (67 DAE) houve uma redução acentuada na taxa de 
senescência das folhas, que, associado ao aumento em expansão das folhas proporcionaram um incremento do dossel vegetativo da cultura. Plantas submetidas a déficit hídrico terminal apresentaram uma redução acentuada na área fotossinteticamente ativa devido a menor taxa de elongação das folhas durante o período de crescimento vegetativo (Figura 1), menor número de folhas (Figura 3) e, principalmente, maior senescência das folhas (Figura 4).

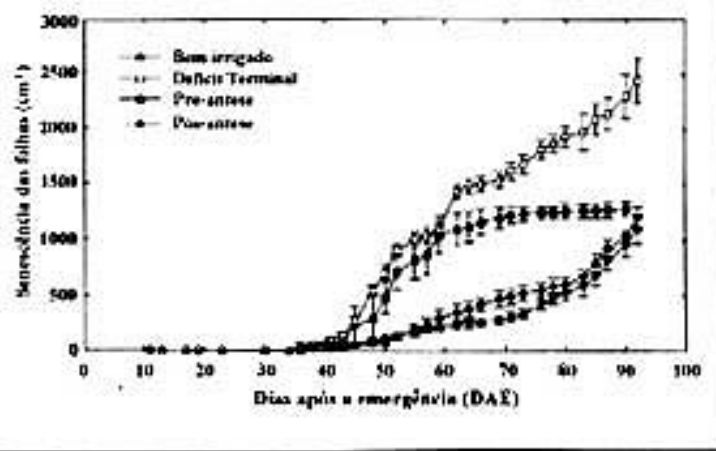

Fïgura 4- Senescència das plantas de sorgo durante o ciclo de ucsenvolvimento para os diferenles mancjos da água de irrigackb. A amplitude das barras vericais representa o desvio padrato. Santa Maria-RS. 1904.

Plantas submetidas a déficit hídrico após a antese apresentaram um incremento na senescência das folhas em relação a plantas bem irrigadas. Porém, a redução no índice de área foliar causado pela senescência foi semelhante para os dois tratamentos, embora tenha ocorrido uma grande redução na quantidade de água disponível para plantas submetidas a déficit terminal (Figura 2). Estes resultados concordam com os relatados por RITCHIE (1981) e CARLESSO (1993) que salientaram haver reduções significativas no desenvolvimento da cultura e, conseqüentemente, no seu rendimento, para valores de FAD abaixo de 0,50.

\section{CONCLUSÕES}

A redução na área fotossinteticamente ativa das plantas da cultivar de sorgo Agroceres 3001 é reduzida quando a fração de água disponível às plantas for inferior a 0,60 , na profundidade do solo explorado pelo sistema radicular das plantas.

O comprimento final dos entre-nós das plantas é reduzido quando da ocorrência de déficit hídrico a partir e durante a fase de crescimento vegetativo, podendo este ser utilizado como indicador do nível de intensidade de ocorrência do déficit hídrico em plantas de sorgo.
A senescência das plantas de sorgo é maior para déficits hídricos aplicados a partir e durante a fase de crescimento vegetativo das plantas e é ativado quando a fração de água disponível às plantas for inferior a 0,50 na profundidade do solo explorado pelo sistema radicular das plantas.

\section{REFERÊNCIAS BIBLIOGRÁFICAS}

ARKIN, G.F., VANDERLIP, R.L., RITCHIE, J.T. A dynamic grain sorghum growth model. Transactions of ASAE, St. Joseph, p. 622-626. 1976.

ASSOCIAÇÃO BRASILEIRADE MILHO E SORGO. Sorgo granífero, cultivo e utilização. Pelotas, Grupo Pró-Sorgo - Sul, 1989. 41p.

CARLESSO, R. Influence of soil water deficits on maize growth and leaf area adjustments. East Lansing - Michigan. 253 p. Tese (Doutorado) - Michigan State University, 1993.

CARLESSO, R. Absorção de água pelas plantas, água disponível versus extraível e a produtividade das culturas. Ciência Rural, Santa Maria, v. 25, n. 1, p. 183-188, 1995.

DOORENBOS, J., PRUITT, W.O. Crop water requirements. Rome: Food and Agricultural Organization of the United Nations. 1977. 179p. (Irrigation and Drainage Paper 24).

FERREIRA, L.G.R., ALBUQUERQUE, I.M., CRUZ, M.G.M. Alterações na produção de sorgo em resposta ao estresse hídrico aplicado em diferentes fases do ciclo vital. Engenharia Rural, Piracicaba, v. 3, n. 2, p. 50-64, 1992.

NeSMITH, D.S., RITCHIE, J.T. Effects of soil water-deficits during tassel emergence on development and yield component of maize (Zea mays). Fields Crops Research, Amsterdam, v.28, p. 251-256, 1992.

MUCHOW, R.C., CAMBERRY, P.S. Environmental control of phenology and leaf growth in a tropical grain sorghum. Field Crop Research, Amsterdam, v. 23, p. 221-237, 1990.

PEITER, M.X., CARLESSO, R. Comportamento do sorgo granífero em função de diferentes frações de água disponível no solo. Ciência Rural, Santa Maria, v. 26, n. 1, p. 51-55, 1996.

RITCHIE, J.T. Water dynamics in the soil-plant-atmosphere system. Plant and Soil, The Hage, v. 58, p. 81-96, 1981.

ROSENTHAL, W.D., ARKIN, G.F., SHOUSE, P.J., et al. Water deficit effects on transpiration and leaf growth. Agronomy Journal, Madison, v. 79, p. 1019-1026, 1987.

STOUT, D.G., KANNAGARA, T., SIMPSOM, G.M. Drought resistence of Sorghum bicolor. II. Water stress effects on growth. Canadian Journal of Plant Science. v. 58, p. 225233, 1978.

STICKLER, F.C., WEARDEN, S., PAULI, A.W. Leaf area determination in grain sorghum. Agronomy Journal, Madison, v. 53, p. 187-188, 1961.

WOLFE, D.W., HENDERSON, D.W., HSIAO, T.C. $\boldsymbol{e}$ t al. Interactive water and nitrogen effects on senescence of maize. I. Leaf area duration, nitrogen distribution, and yield. Agronomy Journal, Madison, v. 80, p. 859-864, 1988. 